\title{
СТРУКТУРНО-ЛІНГВІСТИЧНИЙ ПІДХІД ДО КЛАСИФІКАЦІЇ КАРДІОРИТМОГРАМ У СПОРТСМЕНІВ ВИСОКОЇ КВАЛІФІКАЦІЇ В ПОЧАТКОВУ ФАЗУ АДАПТАЦІЇ ДО УМОВ СЕРЕДНЬОГІР'Я
}

\author{
В. М. Ільїн1, Л. І.Черкес ${ }^{2}$, М. Михайлович ${ }^{3}$, В. І. Портніченко², І. А. Яхниця \\ Національна медична академія післядипломної освіти імені П. Л. Шупика ${ }^{1}$ \\ Міжнародний центр астрономічних і медико-екологічних досліджень НАН України \\ Чернівецький національний університет імені Ю. Федьковича
}

\begin{abstract}
Вивчено можливість використання структурно-лінгвістичного методу для класифікації спектрів потужності варіабельності серцевого ритму у висококваліфікованих спортсменів, які спеціалізуються на швидкісно-силових видах легкої атлетики. Показано можливість оцінки адаптаційних реакцій термінової адаптації організму людини до умов гірської гіпоксії за допомогою системи формульного запису, яка містить символи, що характеризують структуру спектра, частотні та амплітудні характеристики основних спектральних максимумів.
\end{abstract}

Ключові слова: серцевий ритм, спектральна формула, функціональний стан, гіпоксія, адаптація.

\section{СТРУКТУРНО-ЛИНГВИСТИЧЕСКИЙ ПОДХОД К КЛАССИФИКАЦИИ КАРДИОРИТМОГРАММ У СПОРТСМЕНОВ В Ы СОКОЙ КВАЛИФИКАЦИИ В НАЧАЛЬНУЮ ФАЗУ АДАПТАЦИИ К УСЛОВИЯМ СРЕДНЕГОРЬЯ}

\author{
В. Н. Ильин ${ }^{1}$, Л. И. Черкес ${ }^{2}$, М. Михайлович ${ }^{3}$, В. И. Портниченко ${ }^{2}$, И. А. Яхница \\ Национальная медицинская академия последипломного образования имени П. Л. Шупи- \\ Международный центр астрономических и медедко-экологических исследований НАН \\ Украины ${ }^{2}$ \\ Черновицкий национальный университет имени Ю. Федьковича ${ }^{3}$
}

\begin{abstract}
Изучена возможность использования структурно-лингвистического метода для классификации спектров мощности вариабельности сердечного ритма у высококвалифицированных спортсменов, специализирующихся в скоростно-силовых видах легкой атлетики. Показана возможность оценки адаптационных реакций срочной адаптации организма человека к условиям горной гипоксии с помощью системы формульной записи, содержащей символы, характеризующие структуру спектра, частотные и амплитудные характеристики основных спектральных максимумов.
\end{abstract}

Ключевые слова: сердечный ритм, спектральная формула, функциональное состояние, гипоксия, адаптация.

\section{THE STRUCTURAL LINGUISTIC APPROACH TO CARDIAC RHYTHM CLASSIFICATION FOR ATHLETES DURING THE INITIAL ADAPTATION STAGE TO ALTITUDE CONDITIONS}

\author{
V. M. Ilyin ${ }^{1}$, L. I.Cherkes ${ }^{2}$, M. Myhaylovych ${ }^{3}$, V. I. Portnichenko², I. A. Yahnytsia ${ }^{2}$ \\ National Medical Academy of Post-Graduate Education by P. L. Shupyk ${ }^{1}$ \\ International centre for Astronomy and Medical and Ecological Studies of NAS Ukraine ${ }^{2}$ \\ Chernivtsi National University by Yu. Fedkovych ${ }^{3}$
}

\begin{abstract}
We have implemented the structural and linguistic approach to study the cardiac rhythm variability of athletes competing in speed- power disciplines. The athletes were subjected to altitude- induced hypoxia. We have derived the formula that describes the adaptation reactions and the key characteristics of the cardiac rhythm spectrum, such as frequency and amplitudes of main spectral maxima.
\end{abstract}

Key words: cardiac rhythm, spectrum analysis, functional state, hypoxia, adaption.

(c) В. М. Ільїн, Л. І.Черкес, М. Михайлович, В. І. Портніченко, І. А. Яхниця 
Вступ. Організм людини має унікальну властивість пристосовуватися до змін зовнішнього і внутрішнього середовища, у тому числі і до фізичних навантажень. Одним з механізмів процесу адаптації до фізичних навантажень $є$ варіабельність функціонування фізіологічних систем, зокрема, варіабельність серцевого ритму спортсмена $[1,2]$.

Хоча останнім часом є велика кількість досліджень, що використовують методи спектрального аналізу варіабельності серцевого ритму, які дозволяють виявити особливості частотної структури серцевого ритму при дії на організм різних чинників, проте при цьому недостатній акцент ставиться на зміни форми спектра і закономірності його перетворення [3-9 ].

У роботі запропоновано вдосконалений підхід до оцінки функціонального стану організму людини, який включає як сформовані уявлення про регуляторні системи організму, так і положення про те, що організм людини - ультрастабільна система [10].

Мета роботи - апробація структурно-лінгвістичного методу оцінки адаптаційних реакцій термінової адаптації організму людини до умов гірської гіпоксії на прикладі висококваліфікованих спортсменів, які спеціалізуються на швидкісно-силових видах легкої атлетики.

Основна частина. В умовах середньогір'я, на висоті 2100 м, на базі Ельбруської медико-біологічної станції Міжнародного центру астрономічних і медико-екологічних досліджень НАН України на 2-3-тю добу перебування в горах обстежено 12 спортсменів, кваліфікації майстер спорту і майстер спорту міжнародного класу, членів збірної України, що спеціалізуються на бігу на 400 і 800 м. Всі обстежені спортсмени брали участь в кардіоритмографічному обстеженні в стані відносного спокою лежачи і під час проведення активної ортостатичної проби (АОП).

Відповідно до «Міжнародного стандарту» [11] в дослідженнях тривалість запису кардіоритмограми (КРГ) становила 5 хвилин (300 с). При проведенні АОП аналізували як нестаціонарну ділянку КРГ, що характеризує перехідний процес після прийняття положення стоячи тривалістю 1 хвилина, так і наступної стаціонарної ділянки. Розраховували статистичні характеристики динамічного ряду кардіоінтервалів: кількість кардіоінтервалів (Ы); математичне очікування динамічного ряду стандартне відхилення нормальних величин КЯ інтервалів (80МК), коефіцієнт варіації (СУ); частка послідовних КЯ інтервалів, різниця між якими перевищує 50 мс ${ }^{\wedge} \mathrm{NN} 50, \%$ ). Числовими характеристиками варіаційної пульсограми є: «Мода» (Мо), «Амплітуда моди» (АМо),
«Індекс напруженості» (IH), «Індекс вегетативної регуляції» (IBP), «Вегетативний показник ритму» (ВПР), «Показник адекватності процесів регуляції» (ПАПР).

Для оцінки функціонального стану організму застосовано структурно-лінгвістичний метод [12], заснований на положенні, що організм людини являє собою ультрастабільну систему [1, 10, 13]. При зовнішніх впливах або спонтанно перехід між станами організму відбувається стрибкоподібно за певними правилами. Ці стани і правила переходу класифіковано та описано за допомогою спектральних формул та індексів, хвильових чисел і комплексу математико-статистичних показників серцевого ритму [13-15].

В основу класифікації спектрів потужності серцевого ритму у цій роботі покладено систему формульного запису, що містить символи, які характеризують структуру спектра, частотні та амплітудні характеристики основних спектральних максимумів [13-15].

При аналізі КРГ спортсменів, зареєстрованих в початкову фазу адаптації до умов середньогір'я в спокої і під час функціональних навантажень, визначені 12 iз 16 можливих типів спектрів потужності серцевого ритму, а саме $8 \mathrm{o}, 8 \mathrm{~b}$, БЪВ ${ }^{\wedge}$

На рисунку 1 подано приклади деяких із цих типів спектрів потужності. На рисунку 2 наведено гістограму розподілу типів спектрів потужності серцевого ритму.

Найчастіше зустрічалися спектри типу $\mathrm{SmSbSf}$ $(16,7 \%)$ i $\operatorname{Sm}(13,9 \%)$. Привертає увагу наявність спектрів із вираженим надвисокочастотним компонентом (SmSfSb. SbSfSm, SfSmSb). Вони становлять $14 \%$ від усіх зареєстрованих спектрів, що свідчить про наявність у початковий період адаптації до гірських умов у частини спортсменів великої кількості нестійких станів, які характеризуються високим функціональним напруженням регуляторних механізмів і підвищеним ризиком спонтанного переходу у стани перенапруження і виснаження [16].

Оскільки багато кардіоритмограм із різними спектрами потужності мали дуже близькі математикостатистичні показники, вони були об'єднані в п'ять груп. Надалі замість 12 спектрів аналізували п'ять об'єднаних груп спектрів: 1 - SmSb, SmSbSf; 2 - SbSm, SbSmSf, 3 - So, 4 - Sm, SmSf, SmSfSb, SfSmSb, 5 $\mathrm{Sb}$; SbSf, SbSfSm.

На рисунку 3 наведено частоту зустрічальності різних типів спектрів потужності кардіоритмограм за різних умов їх реєстрації. 

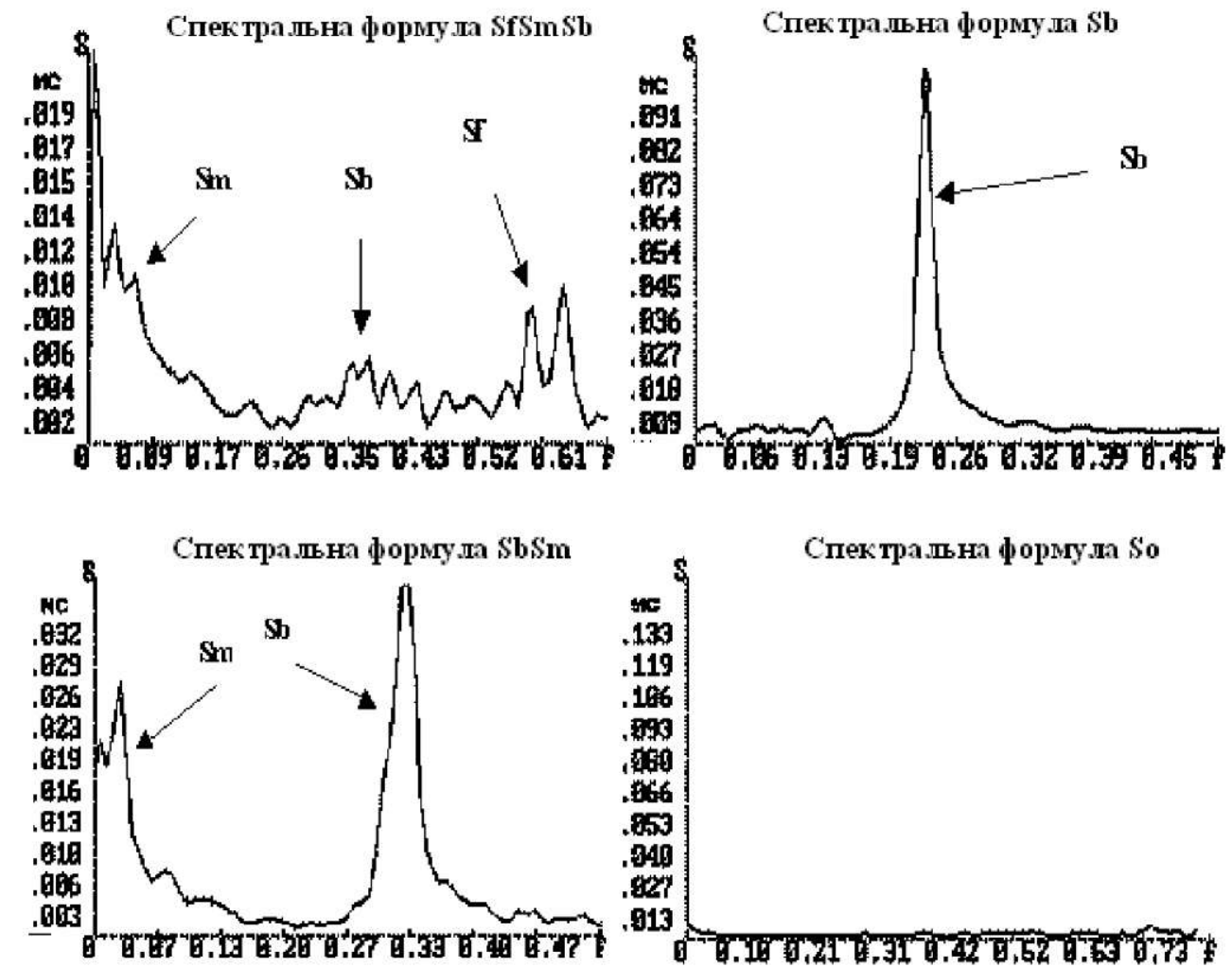

Puc. 1. Приклади спектрограм різного типу, зареєстровані у спортсменів у початковий період адаптації до гірських умов.

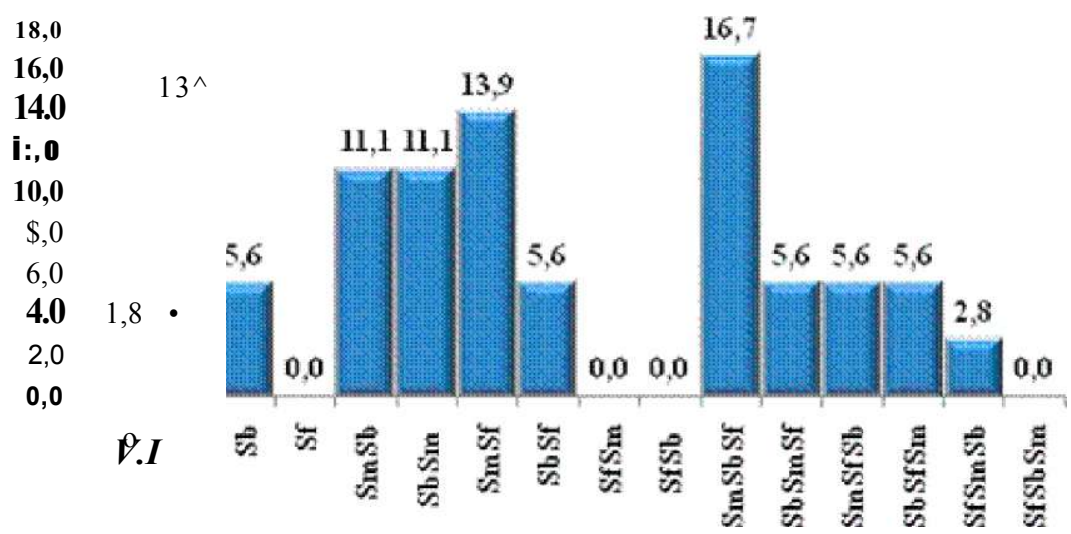

Puc. 2. Частота зустрічальності різних типів серцевого ритму у спортсменів у початковий період адаптації до гірських умов.

Кардіоритмограми зі спектрами 8о,

8 i5т8b зустрічалися частіше під час функціональних навантажень, ніж у стані спокою.

У таблиці 1 наведено математико-статистичні показники, які описують розподіл кардіоінтервалів у кардіоритмограмах у групах із різними типами спектрів.

За допомогою показника активності регуляторних систем (ПАРС) проведено оцінку ступеня напруги регуляторних систем залежно від класу кардіорит- мограми і типу спектра потужності серцевого ритму (див. табл. 1). Показано, що при кардіоритмограмах зі спектрами 8ь8ш, $\quad$ 8ш8b, SmSbSf значення ПАРС не перевищують 4 бали. За шкалою, розробленою Р. М. Баєвским та ін. [13, 17], ця сума балів відповідає стану оптимальної напруги регуляторних систем організму. При спектрах $\mathrm{Sm}$, $\mathrm{SmSf}, \mathrm{SmSfSb}$ i SfSmSb значення ПАРС досягає 5 балів. Це свідчить про функціональну напругу регуляторних систем організму. При спектрі So ПАРC 

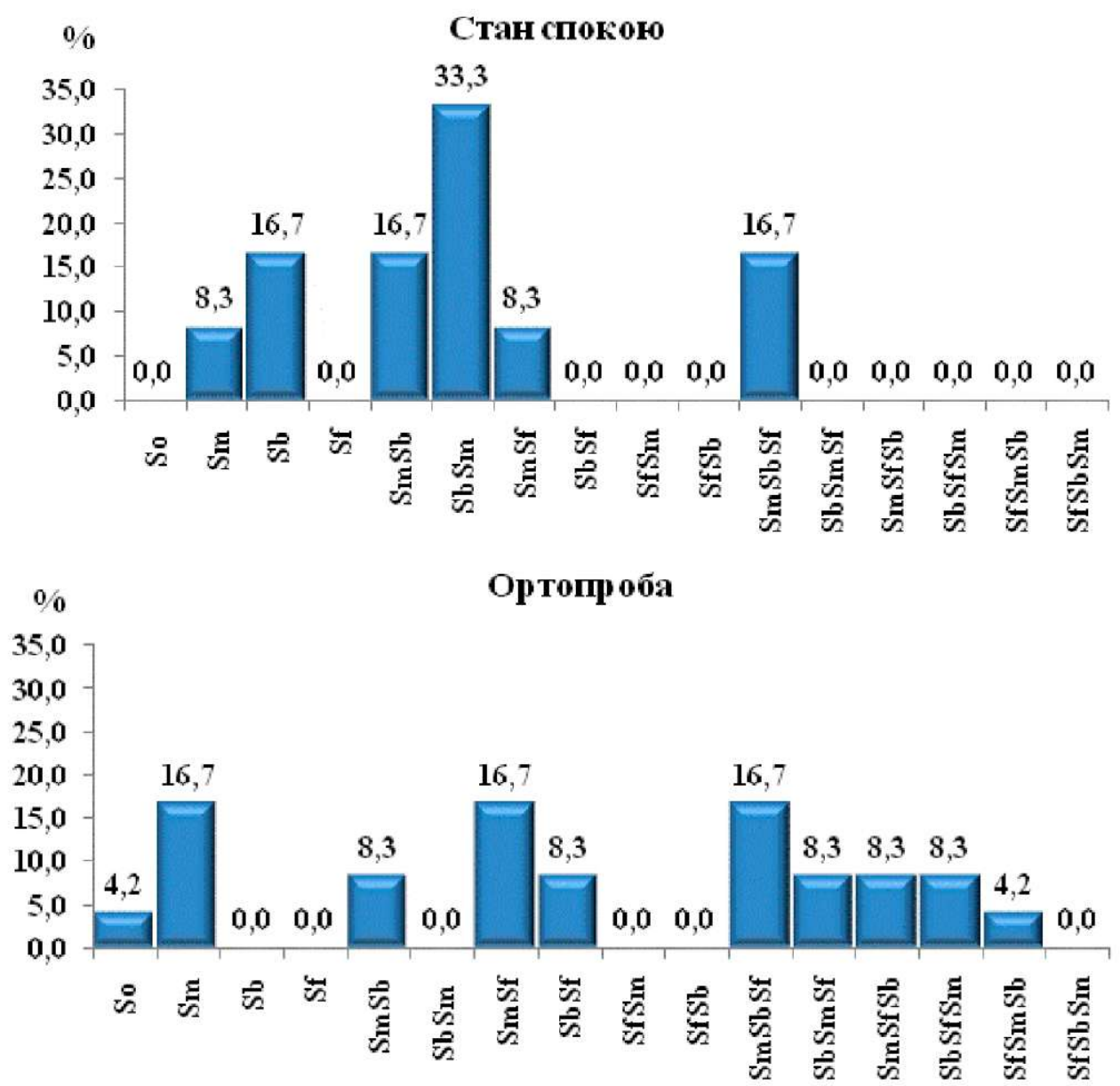

Puc. 3. Розподіл типів спектрів серцевого ритму в спортсменів у початковий період адаптації до гірських умов у стані відносного спокою і під час функціональних навантажень.

Таблиця 1. Математико-статистичні показники, які характеризують розподіл кардіоінтервалів у кардіоритмограмах із різними спектрами потужності серцевого ритму

\begin{tabular}{|l|c|c|c|c|c|}
\hline \multicolumn{1}{|c|}{ Показники } & $\begin{array}{c}\text { Sm, SmSf, } \\
\text { SmSfSb, SfSmSb }\end{array}$ & SmSb, SmSbSf & Sb, SbSf, SbSfSm & So & SbSm, SbSmSf \\
\hline Mo, мс & 657 & 702 & 718 & 734 & 780 \\
\hline RRNN, мс & 681 & 754 & 765 & 735 & 826 \\
\hline SDNN, мc & 25,5 & 19,8 & 18,5 & 12,0 & 41,9 \\
\hline AMo, \% & 48 & 62 & 69 & 87 & 35 \\
\hline$\Delta$ R-R, мc & 395 & 312 & 247 & 207 & 479 \\
\hline CV, \% & 3,7 & 2,7 & 2,5 & 1,7 & 5,1 \\
\hline pNN50, \% & 14,9 & 12,8 & 6,5 & 6,2 & 17,9 \\
\hline IBP & 122 & 199 & 280 & 420 & 73 \\
\hline ПАПР & 71 & 88 & 95 & 123 & 44 \\
\hline ВПР & 3,9 & 4,7 & 5,4 & 6,8 & 2,6 \\
\hline IH & 91 & 143 & 191 & 294 & 47 \\
\hline ПАРC & 5 & 4 & 6 & 8 & 3 \\
\hline \% від вибірки & 29,7 & 24 & 29,7 & 8,5 & 8,1 \\
\hline
\end{tabular}

коливається від 7 до 10 балів. Це вказує на перенапруження або виснаження регуляторних систем. Стани функціональної напруги, перенапруження або виснаження регуляторних механізмів, як і відповідні їм спектри серцевого ритму, частіше зустрічаються під час функціональних навантажень, при виникненні пре- і патологічних станів або при дії екстремальних факторів (рис. 4). 

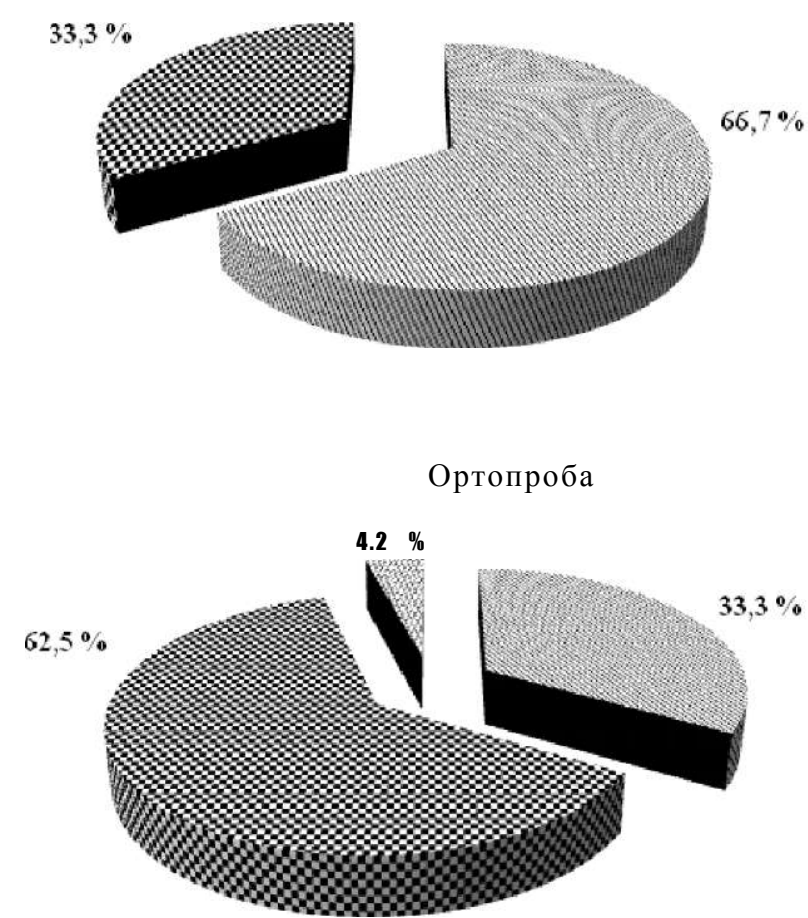

Висновки. 1. В основу класифікації спектрів потужності варіабельності серцевого ритму може бути покладена система формульного запису, що містить символи, які характеризують структуру спектра, частотні та амплітудні характеристики основних спектральних максимумів.

2. При аналізі кардіоритмограм у спортсменів у початковий період адаптації до гірських умов, зареєстрованих у спокої і під час функціональних навантажень, виявлено 12 із 16 можливих типів спектрів по-

\section{Jireparypa}

1. Ільїн В. М. Структурно-лінгвістичний підхід до оцінки функціонального стану організму людини / В. М. Ільїн, В. В. Кальниш, Х. А. Курданов // Доп. НАНУ - 2001 - №> 6. - С. 185-189.

2. Коробейников Г. В. Вариабельность ригма сердца как физиологический механизм адаптации к условиям напряженной мышечной деятельности / Г. В. Коробейников // Материалы 1-й межд. научн. конференции «Анализ вариабельности ритма сердца в клинической практике». - К. : ИПЦ «Аклон», 2002. - С. 68-69.

3. Power spectrum analysis of heart rate fluctuation: a quantitative probe of beat-to-beat cardiovascular control / S. Akselrod, D. Gordon, F. A. Ubel [et al.] // Science. - 1981. Vol. 213, №>4504. - Р. 220-222.

4. Баевский Р. М. Ритм сердца у спортсменов / Р. М. Баевский ; под ред. Р. М. Баевского и Р. Е. Мотылянской. - М. : Физкультура и спорт, 1986. - 143 с.
Puc. 4. Розподіл станів оптимального (COH - SmSb, SшSьSf, SьSш, SьSшSf), функціонального (СФН Sm, SwSf, SwSfSb, SfSшSь, Sb; SbSf, SbSfSш) напруження, перенапруження і виснаження (СП і CB - So) регуляторних механізмів у стані спокою і під час проведення активної ортопроби у спортсменів у початковий період адаптації до гірських умов.

тужності варіабельності серцевого ритму, а саме So, Sb, Sш, SmSb, SшSf, SьSш, SьSf, SшSbSf, SmSfSb, SьSшSf, SbSfSш, SfSшSь.

3. Величини показників, що характеризують кардіоритмограми зі спектрами SшSь, SшSbSf, SbSm i SbSшSf, характерні для функціональних станів організму в нормі. Інші типи спектрів частіше зустрічаються при напругах регуляторних систем організму, що виникають під час функціональних навантажень або під час впливів екстремальних факторів зовнішнього середовища.

5. Кутерман Э. М. Закономерности взаимосвязанных изменений амплитуды и частоты колебательных составляющих ритма сердца / Э. М. Кутерман, Н. Б. Хаспекова // Физиол. человека. - 1989. - Т. 15, №> 5. - С. 48-53.

6. Зависимость характеристик сердечного ритма и кровотока у здоровых и спортсменов с заболеваниями сердечно-сосудистой системы / Д. Жемайтите, А. Кепеженас, А. Мартинкенас [и др.] // Физиология человека - 1998. - 24, № 6. - C. 56-65.

7. Karling P. Spectral analysis of heart rate variability bowel syndrome / P.Karling, H.Nyhlin, U.Wiklund [et al.] // Scand. J. Gastorenterol. - 1998. - Vol. 33, №6 - Р. 572-576.

8. Яблучанский Н. И. Основы практического применения неинвазивной технологии исследования регуляторных систем человека / Н. И. Яблучанский, А. В. Мартыненко, А. С. Исаева. - Х. : Основа, 2000. - 88 с.

9. Михайлов В. М. Вариабельность ритма сердца: опыт 
практического применения метода / В. М. Михайлов. Иваново : Иван. гос. мед. академия, 2002. - 290 с.

10. Эшби У Р. Конструкция мозга/ У Р. Эшби. - М. : Изд. иностранной литературы, 1962. - 398 с.

11. Task Force of the European of Cardiology and the North American Society of Pacing and Electrophysiology. Heart Rate Variability. Standarts of Measurements, Physiological Interpretation, and Clinical Use // Circulation. -1996. - 93.P. 1043-1065.

12. Структурно-лінгвістичний аналіз реакцій організму людини на фізичне навантаження / В. М. Ільїн, Л. І. Черкес, С. Б. Коваль, Г. В. Коробейніков // Медична інформатика та інженерія. - 2009. - №> 3. - С. 48-54.

13. Структурно-лингвистический подход к оценке функционального состояния организма человека в условиях высокогорья / В. Н. Ильин, Л. М. Батырбекова, М. Х. Курданова, Х. А. Курданов. - М. : Илекса; Ставрополь: Сервисшкола, 2003. - 80 c.

14. Криворученко Е. В. Новый подход к оценке работоспособности спортсменов, специализирующихся в цикличес- ких видах спорта, по анализу показателей вариабельности сердечного ритма / Е. В. Криворученко, В. Н. Ильин // Сб. материалов международной научн. конф. Состояние и перспективы развития медицины в спорте высших достижений «СпортМед-2006». - М. : АнитаПресс, 2006. - С. 171 -172 .

15. Ефанова Ю.К. Классификация функциональных состояний организма квалифицированных гребцов методом структурно-лингвистического анализа вариабельности сердечного ритма / Ю. К. Ефанова, В. Н. Ильин // Мат. IX міжнародного наук. конгресу «Олімпійський спорт і спорт для всіх», Київ, Україна, 20-23 вересня, 2005 р. - С. 662.

16. Ilyin $\mathrm{V}$ The structure-linguistic approach to evaluation of functional state of human organism in the extreme conditions / Vllyin, VKalnysh, Y. Gorgo // Сб. трудов конф. « Автоматизированный анализ гипоксических состояний», НальчикМосква, 2003. - С.141-145.

17. Баевский Р. М. Математический анализ изменений сердечного ритма при стрессе / Р. М. Баевский, О. И. Кириллов, С. З. Клецкин. - М. : Наука, 1984. - 221 с. 